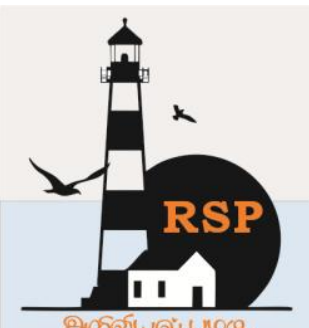

INTERNATIONAL RESEARCH JOURNAL ON ADVANCED SCIENCE HUB

RSP SCIENCE HUB

(The Hub of Research Ideas)

Available online at www.rspsciencehub.com

Special Issue of Second International Conference on Advancements in Research and Development (ICARD 2021)

\title{
Association of BHMT (rs 3733890) gene polymorphism with biochemical markers of B12 deficiency in T2DM patients on metformin therapy
}

Dr. Ananda Vayaravel Cassinadane ${ }^{1}$, Dr. Ramesh Ramasamy ${ }^{2}$

${ }^{1}$ Professor and Principal, Sri Venkateshwaraa College of Paramedical Sciences, Puducherry, India.

${ }^{2}$ Senior Professor, Department of Biochemistry, Jawaharlal Institute of Postgraduate Medical Education and Research, Puducherry, India.

principal@svcpms.ac.in ${ }^{1}$

\begin{abstract}
Long term administration of metformin interferes with the absorption of vitamin B12 resulting in vitamin B12 deficiency.Among the various genetic variants that are associated vitamin B12 deficiency, we analyzed BHMT gene polymorphism and their association with metformin induced vitamin B12 deficiency in T2DM patients. A cross sectional study was done with 300 participants. Methyl malonic acid, homocysteine and high sensitive $C$ reactive protein were analysed by Mass Spectrometry, Chemiluminescent analyser and Immunoturbidimetric method respectively. Genetic variants were analysed by ARMS-PCR method, Data was analyzed with various statistical tools like ROC, Odds ratio and Likelihood ratio. Significant reduction in folic acid and vitamin B12 in metformin users was found. High sensitive $C$ reactive protein, homocysteine and methyl malonic acid are significantly increased in patients with metformin induced B12 deficiency. 'A' allele in BHMT (A allele OR =2.1, AA genotype $=2.8$ ) showed risk of vitamin B12 deficiency in T2DM patients on metformin therapy. BHMT gene polymorphism had LR of 2.65 for folic acid (AG genotype), 2.73 for MMA (AA genotype) and 2.63 for Homocysteine (AA genotype). We found an association between single nucleotide polymorphism of BHMT and diagnosis of vitamin B12 deficiency status in metformin users. Folic acid, MMA and homocysteine had high specificity in concordance with BHMT (rs3733890) polymorphism in predicting vitamin B12 deficiency. Early screening of SNP of BHMT in T2DM patients on metformin therapy will help us to identify group of people who are prone for vitamin B12 deficiency.
\end{abstract}

Keywords:Vitamin B12, Metformin, BHMT, Single nucleotide polymorphism, homocysteine, methyl malonic acid

\section{Introduction}

Type 2 diabetes mellitus (T2DM) rules worldwide, dietary intervention along with pharmacological treatment and regular monitoring of blood glucose being the classical management. Metformin remains the best treatment for T2DM monotherapy, reducing blood glucose levels without inducing overt hypoglycaemia. A high degree of reciprocity occurs in the interrelationship between different vitamins and Diabetes.[1]There is an association between vitamin B12 deficiency and T2DM patients on metformin therapy. Vitamin
B12 decreases with an increase in dosage and also with the duration of administration of metformin. [2] Metformin interferes with vitamin B12 absorption through the alterations in intestinal motility, increased bacterial overgrowth or alterations of vitamin B12-IF complex. The risk of developing metformin induced vitamin B12 deficiency is greatly influenced by the increase in age, metformin dosage, and its duration of use. [3] Vitamin B12 (Cobalamin) plays a vital cofactor role in the synthesis of DNA as well as in two biochemical reactions. Vitamin B12 deficiency 
prevalence varies from $5.8 \%$ to $30 \%$ among patients undergoing long-term treatment with metformin. [4,5]. Metformin induces vitamin B12 deficiency by binding its hydrophobic tail of biguanide to the hydrocarbon core of membranes. The biguanide group gives a positive charge to the membrane and displaces the divalent cations such as calcium. Vitamin B12 uptake into the ileal cells is calcium dependent and can thus be impaired by metformin. [6] Clinical observations indicated a prevalence of $30 \%$ for vitamin B12 malabsorption among patients undergoing long-term metformin therapy. [7]A randomized control trial demonstrating relationship between metformin and serum vitamin B12 found 19\% reduction in serum vitamin B12 levels after 4 years of metformin treatment. [8] Metformin induced vitamin B12 deficiency leads to hematological and neurological complications. [9]. Serum methyl malonic acid (MMA) and homocysteine (Hcy) are the markers used for the diagnosis of vitamin B12 deficiency. [10]The genetic variants altering vitamin B12 status can be studied for the better understanding of the interplay of diet, genetics, and human health in metformin therapy. A twin study reports that the magnitude of genetic influence on serum vitamin B12 levels to be 59\%. [11]. Several genetic studies on vitamin B12 status suggest that it is a multifactorial trait. Single-nucleotide polymorphisms (SNPs) in multiple genes interact with the environment to result in altered B12 status. [12]. BHMT plays role in homocysteine and 1-carbon metabolism. [13-15]It utilizes betaine as the 1-carbon donor. Therefore, mutation of this remethylation enzyme results in elevated homocysteine levels. BHMT is indirectly involved in the folate-dependent pathway. It fluxes homo cysteine when the folate- dependent remethylation is disrupted. [16]. This study also assesses the vitamin B12 status (from homocysteine \& Methyl malonic acid level) between different genotypes of T2DM patients on metformin. In addition, the sensitivity \& specificity of these molecular and biochemical markers are evaluated for predicting vitamin B12 status in T2DM patients on metformin therapy.

\section{Materials and Methods}

The present Cross Sectional Study was carried out at a Tertiary health care setup in Puducherry after obtaining Institutional Ethical Committee approval
(Ref: SVMCH/IEC/2014/48) and written Informed Consent form Study Subjects. 300 T2DM patients on metformin, residing in and around Puducherry in the age group of 35- 55 years of both genders were selected for the study.

2.1 Analysis of Biochemical Variables: A total of $5 \mathrm{ml}$ of venous blood was collected from the patients. $3 \mathrm{ml}$ in a plain tube, $1 \mathrm{ml}$ in EDTA and 1 $\mathrm{ml}$ in heparin tube. Serum sample was collected for analysis of Insulin, vitamin B12, and Folic acid using chemiluminescence in Cobas e411, Roche. Methyl malonic acid was analyzed using LCMS. High sensitive C-reactive protein and plasma glucose (fluoride tube) estimation was done by Immunoturbidometry and glucose oxidase peroxidase method using Diachem 300 plus Autoanalyser. Whole blood was used for estimation of HbA1c and genetic analysis. HbA1c estimated by HPLC method in Bio Rad D10.

2.2 Genetic marker Analysis: Whole blood (2ml) was collected in EDTA tube for the genetic analysis. Genomic DNA was extracted based on spin column kit method. The DNA samples were stored at -20C until analysis.Genotyping for BHMT (rs3733890)variants was carried outthrough ARMS-PCR in a final volume of $20 \mathrm{uL}$ reaction and analyzed by agarose gelelectrophoresis. The sequences of forward and reverse primers were:

Forward:GAGAAGGTGTCTGCGGGCGT [T specific]

Reverse:ACCAAAATGGGGTGGCCAAG Forward:AGGACTCTCTCTGCCCAGTC Reverse:AGCTGCGTGATGATGAAATAGG [C specific]

The PCR steps were a) initial DNA denaturation at $95^{\circ} \mathrm{C}$ for $5 \mathrm{~min}, \mathrm{~b}$ ) denaturation at $95^{\circ} \mathrm{C}$ for $30 \mathrm{sec}, \mathrm{c}$ ) annealingat $63^{\circ} \mathrm{C}$ for $30 \mathrm{sec}, \mathrm{d}$ ) extension at $72^{\circ} \mathrm{C}$ for $30 \mathrm{sec}$ followed by amplification of steps $b$ to fourby 35 cycles and final extension at $72^{\circ} \mathrm{C}$ for $5 \mathrm{~min}$. The PCR final volume of $20 \mathrm{uL}$ reactionsample contained Red dye PCR master mix of $10 \mathrm{uL}$, primer mix $10 \mathrm{uL}$, purified DNA sampleof $5 \mathrm{uL}$. The PCR products were analysed by agarose gel electrophoresis. [Fig:1]

2.3 Statistics: Descriptive and inferential statistical analysis was carried out in the present study. Results onContinuous measurements were presented as mean $\pm \mathrm{SD}$ and results on categorical measurementswere presented in number $\%$. 
www.rspsciencehub.com

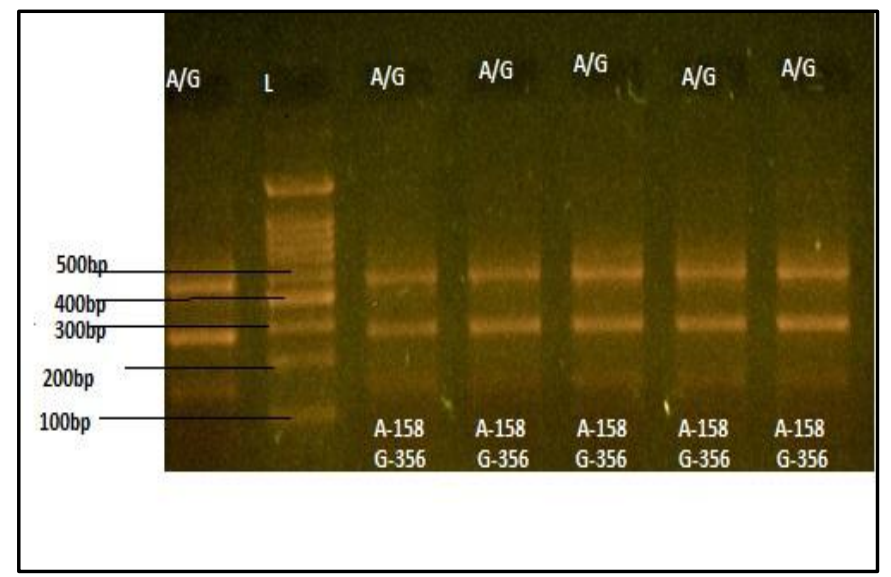

Fig: 1 BHMT gene polymorphism in vitamin B12 deficiency

Lane 1 (ladder - 100bp), Lane 2 AG (A-158, G356), Lane 3,4 AG (A-158, G-356), Lane 5,6 AG (A-158, G-356) Control (599bp)

The data were entered in MS excel sheet so that it can be retrieved easily for analysis using SPSS-16 software. Shapiro-Wilk test was performed to find out the distribution pattern for all the data collected. To compare the biochemical parameters between the groups, independent' $t$ ' Test was performed. $\mathrm{P}$ value less than 0.05 is considered as significant. $\mathrm{t}$ - Test was done to compare the study variables between B12 deficient and non-deficient T2DM patients on metformin. Odds Ratio was performed to study the association between SNP of BHMT and B12 status. One way ANOVA was done to compare the biochemical markers of vitamin B12 status among SNP of BHMT followed by Tukey's hsd Post hoc analysis. ROC curve was plotted and Likelihood Ratio was calculated to study the sensitivity and specificity of these SNPs \& biochemical markers in predicting the vitamin B12 status in T2DM on metformin. All the statistical analyses were done by using statistical software such as IBM SPSS16.0.0 version, Epi Data and Online Med cal.Software: Epi data v2.0, Ms-Excel 2010, SPSS v16.

\section{Results:}

In the present study $300 \mathrm{~T} 2 \mathrm{DM}$ patients on metformin, residing in and around Puducherry between age group 35 and 55 years of both genders were selected. Out of those, 135 patients had a deficiency of vitamin B12 contributing to $45 \%$ of the total of the study population. They were categorized as Group 1 (vitamin B12 deficient population). The other group (165 patients) who had normal levels of vitamin
B12 was categorized as Group 2.Among the Group 1 patients who had a vitamin B12 deficiency, 71 $(53 \%)$ were females and $64(47 \%)$ were males. Among the B12 deficient group, $11 \%$ of them were taking metformin for more than 10 years, $39 \%$ for $5-10$ years and $50 \%$ for less than 5 years. The mean duration of metformin therapy was 7 years. Fifty five percent of the vitamin B12 deficient group was receiving a dose of $1000 \mathrm{mg} /$ day of metformin, $39 \%$ were taking $1500 \mathrm{mg} /$ day and $6 \%$ were taking more than $2000 \mathrm{mg} /$ day of metformin. The mean dosage is $1252 \mathrm{mg}$. Among the group 2 patients (T2DM patients without vitamin B12 deficiency) 107 $(65 \%)$ were males and $58(35 \%)$ were females. Among the 165 T2DM patients whose serum vitamin B12 levels were within the reference range, $93 \%$ were on metformin therapy for less than 5 years, $6 \%$ for $5-10$ years and $1 \%$ of them were taking metformin for more than 10 years. Seventy six percentages of group 2 patients were receiving a dose of $1000 \mathrm{mg} /$ day of metformin, $21 \%$ of the patients $1500 \mathrm{mg} /$ day and $3 \%$ of the T2DM patients without B12 deficiency were receiving more than $2000 \mathrm{mg} /$ day of metformin. The mean dosage of metformin is found to be $1133.33 \mathrm{mg} /$ day. Chi square analysis was performed to find out the duration and dose dependent effect of metformin on the levels of serum vitamin $\mathrm{B} 12$ and the result showed significant difference of $\mathrm{X}^{2}=68.72, \mathrm{p}<0.001$ (Fig:2) and $X^{2}=14.59, p<0.001$ (Fig:3) respectively.

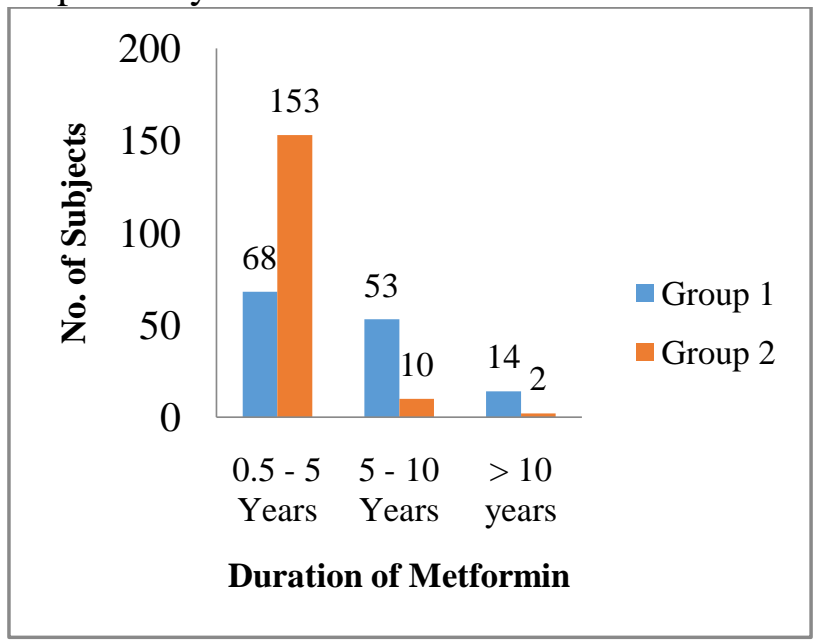

Fig:2 Duration of metformin usage in the Study population

Group 1 - Deficient levels of vitamin B12 Group 2 - Normal levels of vitamin B12 


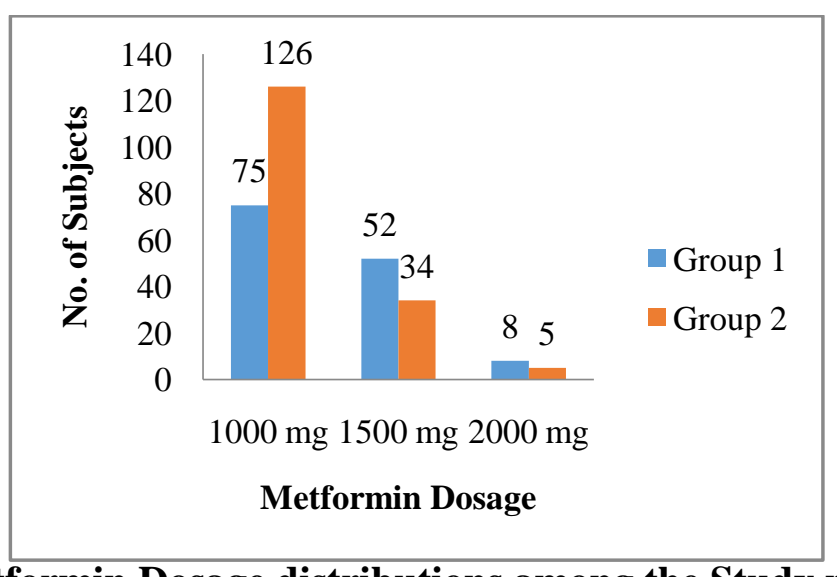

Fig: 3 Metformin Dosage distributions among the Study population

Group 1 - Deficient levels of vitamin B12, Group 2 - Normal levels of vitamin B12, To evaluate the baseline diabetic and vitamin B12 status of the Study population, we have assessed the following parameters. Fasting glucose, fasting insulin,
$\mathrm{HbA1c} \%$, Hs-CRP, vitamin B12, folic acid, homocysteine and methylmalonic acid. The mean values of the various parameters in the two groups have been elucidated in the Table1.

Table: 1.Comparison of the biochemical markers between Group 1 and Group 2

\begin{tabular}{|l|l|l|l|l|}
\hline \multicolumn{1}{|c|}{$\begin{array}{c}\text { BIOCHEMICAL } \\
\text { VARIABLES }\end{array}$} & \multicolumn{1}{|c|}{$\begin{array}{c}\text { Group 1 (135) } \\
\text { MEAN } \text { +SD }\end{array}$} & $\begin{array}{c}\text { Group 2 (165) } \\
\text { MEAN }\end{array}$ & P value & Effect size \\
\hline $\begin{array}{l}\text { Fasting glucose } \\
(\mathrm{mg} / \mathrm{dl})\end{array}$ & $168.5 \pm 35$ & $173 \pm 38$ & 0.2913 & 0.51 \\
\hline $\begin{array}{l}\text { Fasting } \\
\text { insulin(mIU/L) }\end{array}$ & $6.18 \pm 3.03$ & $8.28 \pm 4.18$ & 0.0001 & 0.27 \\
\hline HbA1c \% & $7.9 \pm 0.8$ & $7.7 \pm 0.9$ & 0.0451 & 0.70 \\
\hline Hs-CRP (mg/L) & $2.8 \pm 0.8$ & $1.85 \pm 0.92$ & 0.0001 & 0.3 \\
\hline Vitamin B12 (pg/ml) & $205.23 \pm 48.23$ & $497.50 \pm 148.98$ & 0.0001 & -0.7 \\
\hline Folic acid (ng/L) & $5.1 \pm 3.6$ & $11.03 \pm 3.90$ & 0.0001 & -0.9 \\
\hline $\begin{array}{l}\text { Homocysteine } \\
(\mu \mathrm{mol} / \mathrm{L})\end{array}$ & $25.83 \pm 14.00$ & $12.10 \pm 3.80$ & 0.0001 & 1.32 \\
\hline $\begin{array}{l}\text { Methyl Malonic } \\
\text { Acid(nmol/L) }\end{array}$ & $244.9 \pm .97 .2$ & $183.96 \pm 53$. & 0.0001 & 0.19 \\
\hline
\end{tabular}

Table 1 showed a significant reduction in the levels of vitamin $\mathrm{B} 12$, folic acid $(\mathrm{P}=0.001)$ in group 1 when compared with group 2. Fasting blood sugar is not significant, HbAlc showed significance. Fasting insulin is highly significant. High sensitive $\mathrm{C}$ reactive protein $(\mathrm{P}=0.001)$, homocysteine $(\mathrm{P}=0.001)$ and methyl malonic acid $(\mathrm{P}=0.001)$ are significantly increased in group 1 when compared with group 2 . The primary aim of our study is to evaluate the association of genetic polymorphism of BHMTgene that is associated with vitamin B12 deficiency in T2DM patients on metformin therapy.Association between BHMT (rs3733890) gene polymorphism in T2DM patients on metformin therapy is shown in the Table 2.

Table: 2 Association of Association of BHMT (rs3733890) gene polymorphism in T2DM patients on metformin therapy

\begin{tabular}{|l|l|l|l|l|l|}
\hline Genotype & Group 1 & Group 2 & ORs & 95\% CI & P value \\
\hline GG & $81(60 \%)$ & $128(77 \%)$ & 1 & & \\
\hline AG & $43(32 \%)$ & $31(19 \%)$ & 2.1 & $1.2-3.7$ & $<0.01$ \\
\hline AA & $11(08 \%)$ & $06(04 \%)$ & 2.8 & $1.0-8.1$ & 0.04 \\
\hline AA Vs AG+GG & 54 & 37 & 2.3 & $1.3-3.8$ & 0.01 \\
\hline G & $205(76 \%)$ & $287(87 \%)$ & 1 & & \\
\hline A & $65(24 \%)$ & $43(13 \%)$ & 2.1 & $1.3-3.2$ & $<0.01$ \\
\hline
\end{tabular}


www.rspsciencehub.com

Group 1: T2DM patients with deficient levels of vitamin B12 Group 2: T2DM patients with normal levels of vitamin B12 Chi-Square linear trend analysis showing GG genotype distribution of $128(77 \%)$ in group 2 and $81(60 \%)$ in group 1.AG genotype was found in 31 $(19 \%)$ in group 2 and $43(32 \%)$ group 1. AA genotype was observed in $06(04 \%)$ in group 2 and $11(08 \%)$ in group 1. A significant association

Table: 3 Vitamin B12 deficiency variables versus BHMT gene polymorphism in Group 1 (T2DM patients with deficient levels of vitamin $B 12, n=135$ )

\begin{tabular}{|l|l|l|l|l|}
\hline & \multicolumn{1}{|c|}{ GG } & \multicolumn{1}{c|}{ AG } & \multicolumn{1}{c|}{ AA } & p value \\
\hline N & 81 & 43 & 11 & \\
\hline Folic acid (ng/L) & $5.47 \pm 4.39$ & $4.52 \pm 2.3$ & $4.65 \pm 1.68$ & 0.36 \\
\hline Methylmalonic acid (nmol/L) & $264.16 \pm 95.27$ & $214.37 \pm 98.91$ & $223.27 \pm 74.52$ & 0.01 \\
\hline Homocysteine $(\boldsymbol{\mu m o l} / \mathbf{L})$ & $26.51 \pm 14.28$ & $24.52 \pm 13.57$ & $25.92 \pm 14.6$ & 0.75 \\
\hline hsCRP $(\mathbf{m g} / \mathbf{L})$ & $2.71 \pm 0.85$ & $3.16 \pm 0.72$ & $2.65 \pm 0.94$ & 0.01 \\
\hline Vitamin B12 (pg/ml) & $208.47 \pm 53.35$ & $196.12 \pm 40.6$ & $216.91 \pm 40.6$ & 0.28 \\
\hline
\end{tabular}

One way ANOVA was conducted to compare the biochemical markers within the genotypic variants of BHMT (GG, AG \& AA) in T2DM patients with vitamin B12 deficiency, as shown in Table 3. MMA showed significance $(\mathrm{p}<0.01)$. Post hoc comparisons using the Tukey HSD test indicated that the GG genotype was significant with AG with a $\mathrm{p}$ value of 0.0172 . HsCRP also showed significance $(\mathrm{p}<0.01)$. Post hoc comparisons using the Tukey HSD test indicated that the GG genotype was significant with $A G$ with a $p$ value

between AA (ORs 2.8 with 95\%CI 1.0-8.1) genotype and A allele (ORs 2.1 with $95 \%$ CI 1.33.2) were found to exist.

3.1 Vitamin B12 deficiency variables versus gene polymorphism

Vitamin B12 deficiency variables versus BHMT gene polymorphism in Group 1 is shown in Table 3.

Table: 4 Vitamin B12 deficiency variables versus BHMT gene polymorphism in Group 2 (T2DM patients with normal levels of vitamin $B 12, n=165$ )

\begin{tabular}{|l|l|l|l|l|}
\hline & \multicolumn{1}{|c|}{ GG } & \multicolumn{1}{c|}{ AG } & \multicolumn{1}{c|}{ AA } & p value \\
\hline Folic acid (ng/L) & 124 & 31 & 10 & \\
\hline $\begin{array}{l}\text { Methylmalonic acid } \\
\text { (nmol/L) }\end{array}$ & $\begin{array}{l}11.35 \pm \\
4.06\end{array}$ & $\begin{array}{l}10.69 \pm \\
3.52\end{array}$ & $8.23 \pm 3.52$ & 0.05 \\
\hline $\begin{array}{l}\text { Homocysteine } \\
(\boldsymbol{\mu m o l} / \mathbf{L})\end{array}$ & $\begin{array}{l}183.68 \pm \\
54.6\end{array}$ & $\begin{array}{l}185.74 \pm \\
64.39\end{array}$ & $\begin{array}{l}163.7 \pm \\
38.85\end{array}$ & 0.52 \\
\hline hsCRP (mg/L) & $11.93 \pm$ & $12.32 \pm$ & $13.54 \pm$ & 0.42 \\
\hline Vitamin B12 (pg/ml) & $1.83 \pm 0.92$ & $1.98 \pm 0.99$ & $1.67 \pm 0.72$ & 0.59 \\
\hline Folic acid (ng/L) & $495.76 \pm$ & $487.06 \pm$ & $\begin{array}{l}551.6 \pm \\
169.67\end{array}$ & 0.478 \\
\hline
\end{tabular}

3.2 Gene polymorphism in predicting vitamin B12 deficiency in T2DM patients on metformin therapy

To find the predictive value of SNPs Likelihood ratio analysis was performed in BHMT gene. AG genotype showed a likelihood ratio of 2.65 for folic acid with a sensitivity of $64.44 \%$ and a

of 0.0116. Vitamin B12 deficiency variables versus BHMT gene polymorphism in Group 2 is shown in Table 4. One way ANOVA was conducted to compare the biochemical markers within the genotypic variants of BHMT (GG, AG \& AA) in T2DM patients with normal levels of vitamin B12, as shown in Table 4. MMA showed significance $(\mathrm{p}<0.05)$. Post hoc comparisons using the Tukey HSD test indicated that the GG genotype was significant with AA with a $\mathrm{p}$ value of 0.0446 .

specificity of $75.68 \%$. GG genotype showed a likelihood ratio of 3.12 for methylmalonic acid with a sensitivity of $69.22 \%$ and a specificity of $77.77 \%$. AA genotype showed Likelihood ratio of 2.63 for homocysteine with a sensitivity of $67.39 \%$ and specificity of $74.34 \%$ 
Table: 5 BHMT gene polymorphism in predicting vitamin B12 deficiency in T2DM patients on metformin therapy

\begin{tabular}{|l|l|l|l|l|l|}
\hline $\begin{array}{c}\text { Biochemical } \\
\text { markers }\end{array}$ & $\begin{array}{c}\text { Geno- } \\
\text { type }\end{array}$ & $\begin{array}{c}\text { Sensitivit } \\
\mathbf{y \%}\end{array}$ & $\begin{array}{c}\text { Specificit } \\
\mathbf{y \%}\end{array}$ & LR & $\begin{array}{c}\text { Accurac } \\
\mathbf{y}\end{array}$ \\
\hline \multirow{4}{*}{ Folic acid } & GG & 61.54 & 66.67 & 1.85 & 63.64 \\
\cline { 2 - 6 } & AG & 64.44 & 75.68 & 2.65 & 69.51 \\
\cline { 2 - 6 } & AA & 63.73 & 70.80 & 2.18 & 67.65 \\
\hline \multirow{2}{*}{$\begin{array}{l}\text { Methyl } \\
\text { malonic } \\
\text { acid }\end{array}$} & GG & 69.22 & 77.77 & 3.12 & 72.33 \\
\cline { 2 - 6 } & AG & 68.89 & 60.71 & 1.75 & 65.75 \\
\cline { 2 - 6 } $\begin{array}{l}\text { Homo } \\
\text { cysteine }\end{array}$ & GG & 65.22 & 76.11 & 2.73 & 71.22 \\
\cline { 2 - 6 } & AG & 61.54 & 66.67 & 1.85 & 63.64 \\
\cline { 2 - 6 } & AA & 67.39 & 64.29 & 1.8 & 64.38 \\
\hline
\end{tabular}

\section{Discussion:}

This study was carried out to explore the genetic interactions in metformin induced vitamin B12 deficiency in T2DM patients. The introduction of certain biomarkers like methyl malonic acid and homocysteine in clinical practice has made the diagnosis of B12 deficiency easier. In addition, we have studied BHMT gene that is responsible for vitamin B12 deficiency in metformin users. Metformin is one of the frequently prescribed drugs for T2DM patients. It has an excellent safety profile, with improvement in cardiovascular morbidity and mortality. It has multiple beneficial effects like altering advanced glycosylation end products when consumed by diabetes patients. [1720]Despite all of metformin's benefits, adverse events may occur. Prolonged usage of this drug results in reduction in vitamin $\mathrm{B} 12$ and folate levels with raise in homocysteine and methyl malonic acid level, for which some researchers recommend screening and prevention strategies. After 3-4 months of initiation of metformin therapy, a significant reduction in B12 level occurs quickly, while symptomatic deficiency may take as long as 5-10 years to manifest. [8] This is poorly recognized and not currently screened for or treated by the majority of physicians who prescribe metformin. In view of these considerations, the present study was undertaken to analyze the genetic impact (if any) of vitamin B12 deficiency in T2DM patients who are on metformin therapy. A total of 300 T2DM patients under metformin therapy were included in the study population, based on the inclusion and exclusion criteria. Our study defined biochemical vitamin B12 deficiency as serum levels $\leq 300 \mathrm{pg} / \mathrm{mL} \cdot[18,19]$ When the study population was analyzed for the B12 status, $45 \%$ of the population showed a clear picture of vitamin B12 deficiency. Wile et al study in Canada and Chen et al study in Hong Kong showed a prevalence of B12 deficiency in metformin users of about $31 \%$ and $37 \%$ respectively. [20,21]The deficiency status led to grouping of study population who are having T2DM. Group 1 includes 135 patients who are deficient in vitamin B12 and Group 2 including 165 T2DM patients with normal vitamin B12 level. Among group 1 majority of the population (50\%)were taking Metformin for less than 5 years, compared to those patients who were treated for 6 - 10 years $(39 \%)$ and more than 10 years. Serum vitamin B12 levels were negatively associated with the dosage and duration of metformin use. Ting et al study which included 155 diabetic patients with vitamin B12 deficiency, showed similar association of serum vitamin B12 levels with the dosage and duration of metformin usage, after adjusting for confounding factors [22] while Ko et al study showed a negative correlation with B12 and duration of treatment and no correlation with B12 and dosage.[23]The differences may be accountable for the increased mean duration of metformin therapy which is higher in our study which is 7 years, compared with Beulens et al study where the mean duration ranged from 4 to 5.3 years. [24] The most consistent risk factors in metformin users were the dosage and duration of treatment of the drug. [22,25]. We also studied other parameters related to vitamin B12 
deficiency, such as folate, MMA and homocysteine. Folate is added to our study as it acts as an intermediate in the methionine synthase reaction where vitamin B12 deficiency can trap folate, resulting in folate deficiency. [26] Homocysteine and MMA were analyzed as additional markers to support the evidence of deficiency status. Studies have shown that vitamin B12 also has an antioxidant property. [27] Deficient status of B12 serves as a trigger factor to increase oxidative stress, particularly in patients with diabetes. Therefore inflammatory marker HsCRP was also analyzed as it correlates with hyperhomocysteinemia in B12 deficient population.[28] Our studies identified mean B12 values to be $205.23 \mathrm{pg} / \mathrm{mL}$, significantly lower in metformin treated patients (group 1) while group 2 showed a mean value of $497.50 \mathrm{pg} / \mathrm{mL}$. The mean serum vitamin B12 concentration was 148.6 $\mathrm{pg} / \mathrm{mL}$ in B12 deficient group and $466.1 \mathrm{pg} / \mathrm{mL}$ in B12 normal group as indicated by Rose Zhao-Wei Ting et al study. [22] Although serum vitamin B12 level is the most used test to diagnose deficiency status since 1950s, its sensitivity is not reliable and it can be in the normal range in a significant proportion of population. In such circumstances, serum homocysteine or methylmalonic acid level was considered more sensitive indicators of vitamin B12 status and allows early identification of vitamin B12 deficiency. [29-32] Homocysteine and MMA were elevated in relation to the metformin induced lowering of B12. Homocysteine and MMA had a mean value of $25.83 \mu \mathrm{mol} / \mathrm{L}$ and $244.9 \mathrm{nmol} / \mathrm{L}$ respectively. In our pilot study with 100 metformin users the mean value of Homocysteine and MMA was found to be $12.3 \mu \mathrm{mol} / \mathrm{L}$ and $154.5 \mu \mathrm{mol} / \mathrm{L}$ respectively. [3340. When ROC is used to test the diagnostic utility of biochemical markers in the diagnosis of metformin induced B12 deficiency, it showed that Homocysteine and MMA had maximum AUC of 0.808 (CI:0.753-0.863) and 0.690 (CI:0.628-0.751) respectively with maximum sensitivity and specificity to diagnose B12 deficiency when compared to low folate status. Folic acid is reduced to $5.1 \mathrm{ng} / \mathrm{L}$ in Group 1 when compared to $11.03 \mathrm{ng} / \mathrm{L}$ in group 2. A cross-sectional study with 203 outpatient type 2 diabetic patients, showed a mean range of $17.7 \mathrm{ng} / \mathrm{L}$ of folate concentration. [4] Interaction between vitamin B12 and folate is in the synthesis of methionine from homocysteine by methionine synthase, in which both 5-methyl tetrahydrofolate and methylvitamin-B12 are cofactors. Thus folate cycle, is essential for methylation reactions and for the synthesis of purines and thymidine. Serum folate measurement is nonspecific. Low levels are seen in patients even without the evidence of deficiency. Vitamin B12 and folate deficiency co exists. Low folate status is a risk factor for development of colorectal cancer and other types of cancer. [34]. A study conducted in two hundred and sixteen patients with T2DM on metformin therapy had a HbAlc of mean value of $7.25 \pm$ 1.13. [35] Similarly, our study had a mean value of $7.9 \pm 0.8$ in group 1. Data of this study shows that the patients require a higher metformin dose to attain a mean of $7.9 \%$.

\subsection{Genetic variants}

The diagnostic approach to B12 deficiency includes the demonstration of the deficiency by biochemical investigation and the identification of the cause of the deficiency. The cause analysis would be better if carried from the genetic study. Vitamin B12 status can be altered by several genetic variants by affecting the proteins involved in vitamin B12 absorption, cellular uptake of the vitamin and intracellular metabolism. [36] A twin study showed that the B12 levels had 59\% heritability, indicating the magnitude of genetic influence on vitamin B12 status. [37] The altered B12 status is a cause of multifactorial trait, where several single-nucleotide polymorphisms (SNPs) in multiple genes interact with the environment. [38]There are several genetic variants involved in vitamin B12 deficiency. Among them, BHMT gene is the gene of interest in our study.

4.2 BHMT: Zinc-dependent enzyme, expressed in liver, kidney and lens, takes part in glycine, serine, threonine and methionine metabolism catalyzing the transfer of a methyl group from trimethylglycine and a hydrogen ion from homocysteine to produce dimethylglycine and methionine respectiv ely. Thus it is important in homocysteine and 1carbon metabolism. [39,40] Choline is a source of Betaine and BHMT enzyme substrate. [41] Choline is essential in the formation of S-adenosyl methionine needed for DNA methylation reactions. Defective DNA methylation and impaired DNA 


\section{www.rspsciencehub.com}

repair are the reasons for development of deficiency related complications.[42]Betaine intake can also contribute to reduction in homocysteine level.[43] Mutation occurs at nucleotide 742 in exon 6 of the gene, resulting in replacement of glutamine with arginine in structure of the enzyme.[44, 45]. Re-methylation process of homocysteine to methionine is affected due to mutation in Betaine homocysteine methyltransferase enzyme (BHMT) coding gene, leading to decrease in S-adenosyl methionine (SAM) synthesis, that eventually result in hypomethylation of DNA, chromosome instability, and chromosome miss-segregation serving as a risk factor in B12 deficiency.[46]In our study we found that BHMT polymorphism is associated with T2DM patients on metformin therapy. Our results are in accordance with Finkelstein et al. [47] and we have reported ' $A$ ' allele as a risk factor in T2DM patients on metformin which was found to be a similar risk factor in Indian population. Current study also tried to associate the gene polymorphism of BHMT with the biochemical markers of vitamin B12 deficiency which showed significant increase in the markers like MMA and Homocysteine. Hyperhomocysteinemia is caused by a combination of genetic and nutritional disturbances. Alteration in the function of BHMT results in raised Hcy levels. Schwahn et al study showed high Hcy levels depletes hepatic betaine stores. [48] The oral supplementation of betaine is said lower Hcy concentrations in severe hyperhomocysteinemic patients. [49] The cysteine residues in BHMT function as zinc-binding domains, required for the binding of Hcy to BHMT. Mutation of cysteine residues with alanine or serine results in complete loss of activity. Thus mutated BHMT may lead to accumulation of Hcy levels.[50,51] In our study the frequency of AA genotype was observed in $08 \%$ in group 1 and $04 \%$ in group 2 and when compared to $8 \%$ in case group in Heil et al study. 'A' allele had a maximum odds ratio of 2.1 (95\% CI 1.3-2) with statistically significant $\mathrm{p}$ value $(<0.01)$ in chi square test, suggesting its association with B12 deficiency.

Presence of the homozygous mutated allele AA may result in significant elevation in MMA and non- significant elevation in Hcy levels as in Heil et al study, where AA allele is associated with significant elevation in Hcy levels. [49]Elevated homocysteine levels are risk factors for
Volume 03 Issue 03S March 2021

cardiovascular disease, osteoporosis and dementia.[52]BHMT is not involved directly in the folate-dependent pathway. Hyperhomocysteinemia due to BHMT pathway is enhanced when folatedependent remethylation is disrupted.[53] The diagnostic efficiency of BHMT polymorphism in predicting vitamin B12 status was evaluated by statistical analysis and the results confirmed that A allele had more specificity than sensitivity for diagnosing the deficiency.[54] A high likelihood ratio (LR) for AA and AG genotype suggests that A allele had more probability in predicting the risk of B12 deficiency status and its associated biochemical markers. . LR of A allele for Folic acid is $2.65 ; 2.73$ for MMA and 1.85 for Hcy.

\section{Conclusion}

In our study, we have been able to find the association of rs3733890 in BHMT, genes with vitamin B12 deficiency in T2DM patients who were on metformin therapy. We also observed that the T2DM patients adhering to metformin with homozygous genotypes AA in BHMT genes have significantly lower levels of vitamin B12 together with high risk in developing vitamin B12 deficiency. Decreased Folic acid levels together with increased levels of MMA and Homocysteine were found to have high specificity with the above genetic variations of BHMT (rs3733890) in predicting vitamin $\mathrm{B} 12$ deficiency in T2DM patients on metformin therapy. To conclude, the genetic variants of BHMT (rs3733890) are associated with vitamin B12 deficiency in T2DM patients on metformin therapy. Henceforth, BHMT (rs3733890) can be a good predictor for vitamin B12 deficiency in T2DM patients on metformin therapy. Further studies can be carried out to find out the association of other genes associated with vitamin B12 deficiency in T2DM patients on metformin therapy.

\section{References}

[1]. Mooradian AD, Failla M, Hoogwerf B, Maryniuk M, Wylie-Rosett J. Selected vitamins and minerals in diabetes. Diabetes Care. 1994;17:464-79.

[2].Martin C. The role of vitamins in the prevention and treatment of type 2 diabetes and its complications. J Diabetes Nurs. 2013;17:378-83.

[3]. Wild S, Roglic G, Green A, Sicree R, King H. Global prevalence of diabetes:Estimates for the 
year 2000 and projections for 2030. Diabetes Care.2004;27:1047-53.

[4].Pflipsen MC, Oh RC, Saguil A, Seehusen DA, Seaquist D, Topolski R. The prevalence of vitamin B12 deficiency in patients with type 2 diabetes: a cross-sectional study. J Am Board Fam Med. 2009;22:528-34.

[5].Reinstatler L, Qi YP, Williamson RS, Garn JV, Oakley GP Jr. Association of biochemical B12 deficiency with metformin therapy and vitamin B12 supplements: the National Health and Nutrition Examination Survey, 19992006. Diabetes Care. 2012;35:327-33.

[6]. Adaikalakoteswari A, Jayashri R, Sukumar N, Venkataraman H, PradeepaR,Gokulakrishnan $\mathrm{K}$, et al. Vitamin B12 deficiency is associated with adverse lipid profile in Europeans and Indians with type 2 diabetes. CardiovascDiabetol. 2014;13:129-35.

[7].Singh B, Gupta VK, Venkatesan M, Arora S. Burden of vitamin B12 deficiency in urbanpopulation in Delhi, India: A hospital based study. International Journal of Pharma and Biosciences. 2011;2:521-8.

[8].Bauman WA, Shaw S, Jayatilleke E, Spungen AM, Herbert V. Increased intake of calcium reverses vitamin B12 malabsorption induced by metformin. Diabetes Care.2000;23:1227-31.

[9]. Tomkin GH, Hadden DR, Weaver JA, Montgomery DA. Vitamin B12 status of patients on long-term metformin therapy. $\mathrm{Br}$ Med J. 1971;2:685-7.

[10].Hoffbrand A. Megaloblastic anemias. In: FauciAS,Braunwald E, Kasper DL, Hauser SL, Longo DL, Jameson JL, et al, editors. Harrison's principles of internal medicine, vol. I, 18th ed. USA: McGraw-Hill Companies. Inc; 2012. p. 862-70.

[11].Vogiatzoglou A, Oulhaj A, Smith AD, Nurk E, Drevon CA, Ueland PM, et al. Determinants of plasma methylmalonic acid in a large population: implications for assessment of vitamin B12 status. Clin Chem. 2009;55:2198206.

[12].Lloyd-Wright Z, Hvas AM, Møller J, Sanders TA, Nexø E. Holotranscobalamin as an indicator of dietary vitamin B12 deficiency. Clin Chem. 2003;49:2076-8.

[13].Tanaka T, Scheet P, Giusti B, Bandinelli S, Piras MG, Usala G, et al. Genome-wide association study of vitamin B6, vitamin B12, folate, and homocysteine blood concentrations. Am J Hum Genet. 2009;84:477-82.

[14].Grarup N, Sulem P, Sandholt CH, Thorleifsson

AhluwaliaTS,SteinthorsdottirV,etal.Genetic architecture of vitamin B12and folate levels uncovered applying deeply sequenced large datasets. PLoS Genet.2013;9:e1003530.

[15].Teng YW, Mehedint MG, Garrow TA, Zeisel $\mathrm{SH}$. Deletion of betaine-homocysteine Smethyltransferase in mice perturbs choline and 1-carbon metabolism,resulting in fatty liver and hepatocellular carcinomas. J Biol Chem. 2011;286:36258-67.

[16].Sunden SL, Renduchintala MS, Park EI, Miklasz SD, Garrow TA. Betainehomocysteine methyltransferase expression in porcine and human tissues and chromosomal localization of the human gene. Arch BiochemBiophys. 1997;345:171-4.

[17].Wild S, Roglic G, Green A, Sicree R, King H. Global prevalence of diabetes:Estimates for the year 2000 and projections for 2030. Diabetes Care. 2004;27:1047-53.

[18].Pflipsen MC, Oh RC, Saguil A, Seehusen DA, Seaquist D, Topolski R. The prevalence of vitamin B12 deficiency in patients with type 2 diabetes: a cross-sectional study. J Am Board Fam Med. 2009;22:528-34.

[19].Reinstatler L, Qi YP, Williamson RS, Garn JV, Oakley GP Jr. Association of biochemical B12 deficiency with metformin therapy and vitamin B12 supplements: the National Health and Nutrition Examination Survey, 19992006. Diabetes Care. 2012;35:327-33.

[20].Baik HW, Russell RM. Vitamin B12 deficiency in the elderly. Annu Rev Nutr. 1999;19:357-77.

[21].Yajnik CS, Deshpande SS, Lubree HG, Naik SS, Bhat DS, Uradey BS, et al. Vitamin B12 deficiency and hyperhomocysteinemia in rural and urban Indians. J Assoc Physicians India. 2006;54:775-82.

[22].Kapil U, Bhadoria AS. Prevalence of Folate, Ferritin and Cobalamin deficiencies amongst adolescent in India. J Family Med Prim Care. 2014;3:247-9.

[23].Adaikalakoteswari A, Jayashri R, Sukumar N, Venkataraman H, PradeepaR,Gokulakrishnan 
$\mathrm{K}$, et al. Vitamin B12 deficiency is associated with adverse lipid profile in Europeans and Indians with type 2 diabetes. CardiovascDiabetol. 2014;13:129-35.

[24].Singh B, Gupta VK, Venkatesan M, Arora S. Burden of vitamin B12 deficiency in urbanpopulation in Delhi, India: A hospital based study. International Journal of Pharma and Biosciences. 2011;2:521-8.

[25].Bauman WA, Shaw S, Jayatilleke E, Spungen AM, Herbert V. Increased intake of calcium reverses vitamin B12 malabsorption induced by metformin. Diabetes Care.2000;23:1227-31.

[26].Tomkin GH, Hadden DR, Weaver JA, Montgomery DA. Vitamin B12 status of patients on long-term metformin therapy. $\mathrm{Br}$ Med J. 1971;2:685-7.

[27].De Jager J, Kooy A, Lehert P, wulffele MG, van der kolk J, Bets $\mathrm{D}$, et al. Long term treatment with metformin in patients with type 2 diabetes and risk of vitamin B12 deficiency: randomised placebo controlled trial. BMJ. 2010;340:c2181.

[28].Carmel R. Current concepts in cobalamin deficiency. Annu Rev Med 2000;51:357-75.

[29].Oh R, Brown DL. Vitamin B12 deficiency. Am Fam Physician. 2003;67:979-86.

[30].Hoffbrand A. Megaloblastic anemias. In: FauciAS,Braunwald E, Kasper DL, Hauser SL, Longo DL, Jameson JL, et al, editors. Harrison's principles of internal medicine, vol. I, 18th ed. USA: McGraw-Hill Companies. Inc; 2012. p. 862-70.

[31].Bell DS. Metformin-induced vitamin B12 deficiency presenting as a peripheral neuropathy. South Med J 2010; 103: 265-7.

[32].BjorkeMonsen AL, Ueland PM. Homocysteine and methylmalonic acid in diagnosis and risk assessment from infancy to adolescence. Am J ClinNutr. 2003;78:7-21.

[33].Vogiatzoglou A, Oulhaj A, Smith AD, Nurk E, Drevon CA, Ueland PM, et al. Determinants of plasma methylmalonic acid in a large population: implications for assessment of vitamin B12 status. Clin Chem. 2009;55:2198206.

[34].Lloyd-Wright Z, Hvas AM, Møller J, Sanders TA, Nexø E. Holotranscobalamin as an indicator of dietary vitamin B12 deficiency. Clin Chem. 2003;49:2076-8.
[35].Nilsson SE, Read S, Berg S, Johansson B. Heritabilities for fifteen routine biochemical values: findings in 215 Swedish twin pairs 82 years of age or older. Scand J Clin Lab Invest. 2009;69:562-9.

[36].Haggarty P. B-vitamins, genotype and disease causality. ProcNutr Soc. 2007;66:539-47.

[37].Mitchell ES, Conus N, Kaput J. B vitamin polymorphisms and behavior: evidence of associations with neurodevelopment, depression, schizophrenia, bipolar disorder and cognitive decline. NeurosciBiobehav Rev. 2014;47:307-20.

[38].Vayá A, Rivera L, Hernández-Mijares A, de la Fuente M, Solá E, Romagnoli $\mathrm{M}$, et al. Homocysteine levels in morbidly obese patients: its association with waist circumference and insulin resistance. ClinHemorheol Microcirc.2012;52:49-56.

[39].Carmel, R.; Jacobsen, DW. Homocysteine in Health and Disease. Cambridge University Press; New York: 2001.510 pp.

[40].Millian NS, Garrow TA. Human betainehomocysteine methyltransferase is a zinc metalloenzyme. Arch BiochemBiophys. 1998;356:93-8.

[41].Mudd SH, Brosnan JT, Brosnan ME, Jacobs RL, Stabler SP, Allen RH, et al. Methyl balance and transmethylation fluxes in humans. Am J ClinNutr. 2007;85:19-25.

[42].Zeisel SH. Dietary choline deficiency causes DNA strand breaks and alters epigenetic marks on DNA and histones. Mutat Res. 2012;733:34-8.

[43].Ananth CV, Elsasser DA, Kinzler WL, Peltier MR, Getahun D, Leclerc D, et al. New Jersey placental abruption study investigators. Polymorphisms in methionine synthase reductase and betaine-homocysteine Smethyltransferase genes: risk of placental abruption. Mol Genet Metab. 2007;91:104-10.

[44].Zampieri BL, Biselli JM, Goloni-Bertollo EM, Pavarino EC. BHMT G742A and MTHFD1 G1958A polymorphisms and Down syndrome risk in the Brazilian population.Genet Test Mol Biomarkers. 2012;16:628-31.

[45].Amorim MR, Moura CM, Gomes AD, Barboza HN, Lopes RB, Ribeiro MG, et al. Betaine-homocysteine methyltransferase 
$742 \mathrm{G}>\mathrm{A}$ polymorphism and risk of down syndrome offspring in a Brazilian population. Mol Biol Rep. 2013;40:4685-9.

[46].Viollet B, Guigas B, Leclerc J, Hébrard S, Lantier L, Mounier R et al. AMP-activated protein kinase in the regulation of hepatic energy metabolism: from physiology to therapeutic perspectives. ActaPhysiol (Oxf). 2009;196:81-98.

[47].Finkelstein JD, Martin JJ. Methionine metabolism in mammals. Distribution of homocysteine between competing pathways. J Biol Chem. 1984;259:9508-13.

[48].Schwahn BC, Chen Z, Laryea MD, Wendel $\mathrm{U}$, Lussier-Cacan S, Genest J Jr, et al. Homocysteine-betaine interactions in a murine model of 5,10-methylenetetrahydrofolate reductase deficiency. FASEB J. 2003;17:5124.

[49].Heil SG, Lievers KJ, Boers GH, Verhoef P, den Heijer M, Trijbels FJ, et al. Betainehomocysteine methyltransferase (BHMT): genomic sequencing and relevance to hyperhomocysteinemia and vascular disease in humans. Mol Genet Metab. 2000;71:511-9.

[50].Breksa AP 3rd, Garrow TA. Recombinant human liver betaine-homocysteine $\mathrm{S}$ methyltransferase: identification of three cysteine residues critical for zinc binding. Biochemistry. 1999;38:13991-8.

[51].Millian NS, Garrow TA. Human betainehomocysteine methyltransferase is a zinc metalloenzyme. Arch BiochemBiophys. 1998;356:93-8.

[52].Herrmann W. Significance of hyperhomocysteinemia. Clin Lab. 2006;52:367-74.

[53].Schwahn BC, Chen Z, Laryea MD, Wendel U, Lussier-Cacan S, Genest $J$, et al. Homocysteine-betaine interactions in a murine model of 5,10-methylenetetrahydrofolate reductase deficiency. FASEB J.2003;17:512-4.

[54].Finkelstein JD, Martin JJ. Methionine metabolism in mammals. Distribution of homocysteine between competing pathways. J Biol Chem. 1984;259:9508-13. 